\title{
Abstract \\ Evaluation of a Malaria Surveillance System in Hodeidah City, Yemen, 2021
}

\author{
Maeen Abduljalil ${ }^{1}$, MA; Methaq Al-Sada ${ }^{2}$, MA; Moamer hossam Badi ${ }^{2}$, DPhil; Yaser Ahmed Ghalab ${ }^{1}$, MA
}

${ }^{1}$ Yemen Field Epidemiology Training Program, Sana'a, Yemen

${ }^{2}$ National Malaria Control Program, Sana'a, Yemen

\section{Corresponding Author:}

Maeen Abduljalil, MA

Yemen Field Epidemiology Training Program

Sawan-AL-Rbeen street

Sana'a

Yemen

Phone: 96777223464

Email: maeenabdugali128@gmail.com

\section{Abstract}

Background: Despite continuing control and elimination efforts, malaria continues to represent a major public health problem. Evaluation of the Malaria Surveillance System (MSS) is critical to obtain credible data that can be used for providing information. Hodeidah City, Yemen, is a worthy region to conduct an evaluation of the MSS because it has the greatest malaria burden.

Objective: The aim of this study was to determine the usefulness of the MSS and assess its performance in terms of qualitative and quantitative attributes.

Methods: The updated Centers for Disease Control and Prevention guideline was used to evaluate the MSS in Hodeidah City. After desk reviews and in-depth interviews were conducted, self-administered questionnaires with 5-point Likert scale and yes/no questions were used to collect data from stakeholders at four levels. The indicator's score percent was interpreted according to the following criteria: excellent, $\geq 90 \%$; good, $80 \%$ to $<90 \%$; average, $60 \%$ to $<80 \%$; poor, $40 \%$ to $<60 \%$; and very poor, $<40 \%$. EPI info version 7.2 was used to enter and analyze the data.

Results: Thirty-one stakeholders participated; 55\% of the respondents were men. The system was found to be useful (88\%) to portray the trend of malaria and to guide policy and intervention, with excellent scores $(100 \%)$ for timeliness and completeness. The overall simplicity, representativeness, acceptability, and stability scores were $78 \%, 66 \%, 62 \%$, and $61 \%$, respectively, representing an average rank. However, flexibility scored $40 \%$ and sensitivity only scored $5.5 \%$. The overall performance scores for the MSS were average (68\%), good (82\%), and average (73\%) in central, governorate, and district and health facilities, respectively.

Conclusions: Although the MSS was found to be useful and stable, and the data quality and timeliness were deemed excellent, flexibility and sensitivity were considered to be poor. To ensure sustainability of the MSS, there is a need for gradual replacement of donors' funds with governmental funds. Furthermore, enhancing laboratory diagnosis and proper training of health workers should be adopted for improving flexibility and sensitivity.

(iproc 2022;8(1):e36574) doi: 10.2196/36574

\section{KEYWORDS}

malaria; evaluation; surveillance; Yemen 
Edited by Y Khader; this is a non-peer-reviewed article. Submitted 18.01.22; accepted 19.01.22; published 07.02.22.

Please cite as:

Abduljalil M, Al-Sada M, Badi MH, Ghalab YA

Evaluation of a Malaria Surveillance System in Hodeidah City, Yemen, 2021

iproc 2022;8(1):e36574

URL: https://www.iproc.org/2022/1/e36574

doi: $\underline{10.2196 / 36574}$

PMID:

CMaeen Abduljalil, Methaq Al-Sada, Moamer hossam Badi, Yaser Ahmed Ghalab. Originally published in Iproceedings (https://www.iproc.org), 07.02.2022. This is an open-access article distributed under the terms of the Creative Commons Attribution License (https://creativecommons.org/licenses/by/4.0/), which permits unrestricted use, distribution, and reproduction in any medium, provided the original work, first published in Iproceedings, is properly cited. The complete bibliographic information, a link to the original publication on https://www.iproc.org/, as well as this copyright and license information must be included. 